\title{
Comparison of Bioethanol Preparation from Triticale Straw Using the Ionic Liquid and Sulfate Methods
}

\author{
Małgorzata Smuga-Kogut ${ }^{1}$ (), Bartosz Walendzik ${ }^{2}$ (), Daria Szymanowska-Powalowska ${ }^{3, *}$, \\ Joanna Kobus-Cisowska ${ }^{4}$, Janusz Wojdalski ${ }^{5}{ }^{\mathbb{D}}$, Mateusz Wieczorek ${ }^{6}$ and \\ Judyta Cielecka-Piontek ${ }^{6}$ (D) \\ 1 Department of Agrobiotechnology, Faculty of Mechanical Engineering, Koszalin University of Technology, \\ Raclawicka 15-17, 75-620 Koszalin, Poland; malgorzta.smuga-kogut@tu.koszalin.pl \\ 2 Faculty of Civil Engineering, Environmental and Geodetic Sciences, Koszalin University of Technology \\ Koszalin, Sniadeckich 2, 75-453 Koszalin, Poland; bartosz.walendzik@tu.koszalin.pl \\ 3 Department of Biotechnology and Food Microbiology, Poznan University of Life Sciences, \\ Wojska Polskiego 48, 60-627 Poznan, Poland \\ 4 Department of Gastronomical Sciences and Functional Foods, Poznan University of Life Sciences, \\ Wojska Polskiego, 60-637 Poznan, Poland; joanna.kobus-cisowska@up.poznan.pl \\ 5 Department of Production Management and Engineering, Faculty of Production Engineering, \\ Warsaw University of Life Sciences, Nowoursynowska 166, 02-787 Warsaw, Poland; \\ janusz_wojdalski@sggw.pl \\ 6 Department of Pharmacognosy, Poznan University of Medical Sciences, Swiecickiego 4, 60-781 Poznań, \\ Poland; mateuszwieczorek23@gmail.com (M.W.); jpiontek@ump.edu.pl (J.C.-P.) \\ * Correspondence: daria.szymanowska@up.poznan.pl
}

Received: 26 January 2019; Accepted: 19 March 2019; Published: 25 March 2019

\begin{abstract}
Triticale straw constitutes a potential raw material for biofuel production found in Poland in considerable quantities. Thus far, production of bioethanol has been based on food raw materials such as cereal seeds, sugar beets or potatoes, and the biofuel production methods developed for these lignocellulose raw materials can threaten the environment and are inefficient. Therefore, this study aimed to compare of methods for pretreatment of triticale straw using 1-ethyl-3-methylimidazolium acetate and the sulfate method in the aspect of ethanol production intended for fuel. Based on the conducted experiments it has been determined that the use of 1-ethyl-3-methylimidazolium acetate for the pretreatment of triticale straw resulted in an increase of reducing sugars after enzymatic hydrolysis and ethyl alcohol after alcoholic fermentation. Furthermore, the study compared the efficiency of enzymatic hydrolysis of triticale straw without pretreatment, after processing with ionic liquid, recycled ionic liquid and using sulfate method, allowing a comparison of these methods. The more favorable method of lignocellulose material purification was the use of ionic liquid, due to the lower amount of toxic byproducts formed during the process, and the efficiency test results of bioethanol production using pretreatment with ionic liquid and sulfate method were similar. Ionic liquid recycling after pretreatment of rye straw using lyophilization allowed us to reuse this solvent to purify rye straw, yet the efficiency of this method remained at a low level. As a result of the conducted study it was determined that the use of ionic liquid-1-ethyl-3-methylimidazolium acetate enhanced the yield of bioethanol from triticale straw from $1.60 \mathrm{~g} / \mathrm{dm}^{3}$ after processing without pre-treatment to $10.64 \mathrm{~g} / \mathrm{dm}^{3}$ after pre-treatment.
\end{abstract}

Keywords: triticale straw; ethanol; ionic liquids; sulfate method 


\section{Introduction}

Lignocellulosic raw materials constitute the most promising group of raw materials for the production of bioethanol. The global amount of lignocellulose waste exceeds 180 billion tons per annum. Lignocellulose contains cellulose, hemicellulose and lignin. The biotechnological processes primarily focus on cellulose, as the product of its hydrolysis is glucose, easily processed by the majority of microorganisms. The mean efficiency of ethanol production from cellulose is $0.42 \mathrm{~m}^{3} /$ ton of $\mathrm{d}$. w . Contrary to the easily hydrolyzed starch, cellulose requires expensive preparation. Hydrolysis with dilute acids (primarily sulfuric acid) is normally used for this purpose. Acidic hydrolysis techniques are used in Brazil and in the USA. Other cellulose raw material processing methods are known (extraction, enzymatic hydrolysis), yet thus far they have remained more expensive. One may hope that as a result of technical progress, less expensive methods of cellulose material saccharification will become available, allowing their transformation into ethanol to become profitable. Considering the high contribution of the raw material to the bioethanol production costs, genetic research, aiming at the increase of productivity of the plants being the potential energy substrate, is essential. Geneticists are constantly conducting research on the development of saccharide-rich, new cultivars of cereals and sugar beet, as well as on the enhancement of the properties related to plant immunity against insects and herbicides [1].

The use of biomass for the energy production constitutes one of the possibilities to reduce the production of conventional energy. Second generation biofuel production is defined as a biomassutilizing technology, conducted in a safe and non-burdensome manner for the environment, reducing the $\mathrm{CO}_{2}$ emissions [2].

The use of agricultural biomass for ethanol production as a biocomponent of liquid fuels is one of the most promising economic and environmental solutions due to the low raw material costs and reduction of greenhouse gas emissions during their combustion [3,4].

However, thus far only a small number of technologies utilizing lignocellulose raw materials for bioethanol production exist, which is strictly related to the structure of the raw material and availability of reducing sugars after the hydrolysis process. The most problematic structural element of lignocellulose is the lignin, which irreversibly binds the active sites of cellulolytic enzymes, thus significantly reducing the efficiency of cellulose hydrolysis reaction, despite the expensive pretreatment $[5,6]$. Chemical pre-treatment is used to remove lignin and separate it from the cellulose fibers. The most common industrial methods are based on the use of active brewing chemicals. The use of acids and bases is efficient and produces expected results, yet it typically generates harmful byproducts. The method which is gathering an increasing interest due to the efficient preparation of the lignocellulose substrate for the fermentation process consists in the use of ionic liquids.

Ionic liquids are organic salts consisting of an organic cation containing a heterocyclic atom and an inorganic or organic anion. Ionic liquids containing imidazolium cations and anions such as chloride, acetate and formate display particularly good cellulose-dissolving properties [7-9]. The literature indicates that thus far the properties of ionic liquids containing different anions and cations have been tested, and their capacity to dissolve cellulose has been examined as well [8-12]. Worth emphasizing is the fact that on annual basis the Polish agriculture sector produced approx. 28.5 million tons of straw (primarily cereal and rapeseed straw) and hay [13] and 30-50\% of the existing resources can be used for energy purposes.

As a plant biomass intended for energy purposes triticale straw requires particular treatment in the ethanol fermentation process. This is linked to its particular structure, in which lignin plays the most important role and it is strictly connected to the remaining cellulose and hemicellulose polymers. This forces the use of substrate pretreatment, which considerably impacts the course of the subsequent stages and determines the final efficiency of the bioethanol production process [14-16].

This study aimed at a comparison of methods for pretreatment of triticale straw using 1-ethyl-3-methylimidazolium acetate and the sulfate method in the aspect of ethanol production intended for fuel. 


\section{Methods}

\subsection{Materials and Reagents}

The study material consisted of triticale straw (Agricultural Holding A. Kogut, Krytno, Zachodniopomorskie Voivodeship, Poland), disintegrated to $2 \mathrm{~mm}$ grain size powder. In order to perform the hydrolysis reaction of the material two enzymatic preparations were used: cellulase from Trichoderma reesei ATCC 26921 (Sigma Aldrich, Poznan, Poland) and cellobiose synthesized by Aspergillus niger (Novozym 188, Sigma Aldrich, Poznan, Poland). To perform pretreatment of the biomass, ionic liquid in the form of 1-ethyl-3-methylimidazolium acetate was used. The enzymatic preparations as well as ionic liquid originated from the Sigma Aldrich Company (Poznan, Poland). In the process of triticale straw purification with the sulfate method, active brewing chemicals consisted of sodium hydroxide and sodium sulfide provided by POCH Company (Gliwice, Poland).

\subsection{Pretreatment Procedure}

Within the conducted study, three raw material pretreatment variants were examined. The first method consisted in preliminary purification of triticale straw using 1-ethyl-3-methylimidazolium acetate. To this aim, triticale straw (100 g) was dissolved in 1-ethyl-3-methylimidazolium acetate $\left(100 \mathrm{~cm}^{3}\right)$. The sample was incubated in $120^{\circ} \mathrm{C}$ for $2 \mathrm{~h}$, then the sample was cooled to room temperature and deionized water $\left(100 \mathrm{~cm}^{3}\right)$ was added to precipitate the cellulose and hemicellulose. The samples were mixed for approx. $30 \mathrm{~min}$, which resulted in the transfer of the 1-ethyl-3-methylimidazolium acetate to the aqueous phase. The water rinsing and mixing processes were repeated three times, until complete removal of the ionic liquid was achieved. In the last stage, the sediment was rinsed with $\mathrm{pH} 4.7$ acetate buffer $\left(100 \mathrm{~cm}^{3}\right)$, subjected to mixing for approx. $15 \mathrm{~min}$, and then decanted.

The second pretreatment method consisted in the so-called delignification of triticale straw using the sulfate method. In this process, the cellulose fibers are released by dissolution of the lignin and part of hemicellulose in the solution of brewing chemicals. The brewing process was conducted at $180^{\circ} \mathrm{C}$ for $4 \mathrm{~h}$. The brewing liquor causes the alkylation of lignin and hence its transformation into alkyl lignin. Cellulose fibers were separated from the chemicals using a vacuum filtration method. The end product of the brewing process was an unbleached cellulose mass, which was used for the subsequent study.

The third pretreatment method for triticale straw consisted in dissolution of $100 \mathrm{~g}$ of d.s. of the substrate in 1-ethyl-3-methylimidazolium acetate $(100 \mathrm{~mL})$ after recycling and incubation of the mixture in $120^{\circ} \mathrm{C}$ for $2 \mathrm{~h}$. Subsequently, the material was precipitated from the solution using distilled water. The substrate with the ionic liquid was cooled to room temperature and distilled water $\left(100 \mathrm{~cm}^{3}\right)$ was added to precipitate the cellulose and hemicellulose. The samples were mixed for approx. $30 \mathrm{~min}$, which resulted in the transfer of the 1-ethyl-3-methylimidazolium acetate into aqueous phase. The water rinsing, and mixing processes were repeated three times, until complete removal of the ionic liquid was achieved.

The 1-ethyl-3-methylimidazolium acetate recycling consisted in desiccation of the solution of this liquid using a lyophilization process. Aqueous ionic liquid solution $\left(100 \mathrm{~cm}^{3}\right)$ frozen at a temperature of $-40{ }^{\circ} \mathrm{C}$ from the last stage of the pretreatment was used for lyophilization. The process was conducted in an Alpha 1-2 LDPLUS laboratory freeze dryer by Christ Company (Berlin, Germany) for $24 \mathrm{~h}$, at a pressure of $63 \mathrm{~Pa}$, and safety pressure of $103 \mathrm{~Pa}$. Following lyophilization a viscous ionic liquid was obtained, which color was similar to the color of pure ionic liquid. Subsequently, the possibility of a repeated use of the retrieved ionic liquid in the pretreatment of a new portion of triticale straw, which was also enzymatically hydrolyzed, was tested. The reducing sugar content results obtained after enzymatic hydrolysis of triticale straw purified with recycled ionic liquid were compared with the contents of reducing sugars determined after enzymatic hydrolysis of rye straw purified with pure ionic liquid. Three repetitions of the tests were conducted, and the results presented in the graph represent a mean value from the three measurements. 


\subsection{Enzymatic Hydrolysis of the Regenerated Triticale Straw}

The raw material after pretreatment with ionic liquid and chemical treatment was hydrolyzed using enzymes obtained from Trichoderma reesei and Aspergillus niger. The substrate (100 g) was suspended in acetate buffer $\left(1 \mathrm{dm}^{3}, 50 \mathrm{mM}, \mathrm{pH} 4.7\right)$ and distributed in the entire volume by mixing in a fermenter for approx. $10 \mathrm{~min}$. Samples were heated to $47^{\circ} \mathrm{C}$ and enzymes were added: cellulase from Trichoderma reesei ATCC 26921 (7 FPU.g ${ }^{-1}$ d.s. of the material) and Novozym 188 cellobiose (Aspergillus niger, $30 \mathrm{CBU} \cdot \mathrm{g}^{-1}$ d.s. of the material). Enzymatic hydrolysis was conducted for $72 \mathrm{~h}$. Then, the hydrolysates were subjected to alcoholic fermentation. At the same time, control samples were prepared, which consisted of rye straw suspensions without pretreatment. Three repetitions of each experimental variant were done. Samples were obtained at determined time intervals and their total reducing sugar content in relation to the content of glucose read from the model curve was determined.

\subsection{Fermentation}

Hydrolysate solutions, previously filtered to separate the lignocellulose residue, were subjected to alcoholic fermentation. The $\mathrm{pH}$ of the fermentation broth was measured at each sampling timepoint and adjusted to 5.0 by an addition of either $10 \mathrm{wt} . \% \mathrm{H}_{2} \mathrm{SO}_{4}$ or $20 \mathrm{wt} . \% \mathrm{NaOH}$. Fermentation was started by an addition of freeze-dried Saccharomyces cerevisiae type II distiller's yeast (Sigma-Aldrich, $5 \% \mathrm{v} / \mathrm{v}$ ). Ethanol fermentation was conducted for 4 days under anaerobic conditions. Samples were taken and analyzed for ethanol concentrations after the fermentation.

\subsection{Analysis Methods}

The concentrations of reducing sugars after enzymatic hydrolysis of cellulose were quantitatively determined using 3,5-dinitrosalicylic acid in an alkaline environment [17]. The vitality and yeast cell counts in digestate were determined using direct method with a light microscope and Thoma chamber and $0.01 \%$ solution of methylene blue. The concentration of ethyl alcohol was determined using a ROCHE test (Enzymatic Bioanalysis/Food Analysis). To evaluate of the course of the hydrolysis and fermentation processes, a multidimensional analysis of primary components (PCA) was used to indicate the significance of the influence of individual factors in the given variant on the efficiency of hydrolysis and the effects of interaction between individual factors. STATISTICA version 10 ((license No.: AGAP306E324317AR-T, StatSoft Inc., Kraków, Poland; www.statsoft.com) software was used for the analysis of the study results.

\section{Results and Discussion}

\subsection{Enzymatic Hydrolysis}

After $72 \mathrm{~h}$, the obtained concentration of released sugars as a result of enzymatic hydrolysis of the native substrate (control sample) was $6.78 \mathrm{~g} / \mathrm{dm}^{3}$ of hydrolysate. As a result of the series of experiments utilizing triticale straw treated with 1-ethyl-3-methylimidazolium acetate a considerable increase in the susceptibility of the substrate to enzymatic hydrolysis was observed. Almost a six-fold higher content of reducing sugars in comparison to the control sample obtained after a 72-hour enzymatic hydrolysis proves the validity of treating the raw material with ionic liquid. The highest reducing sugar concentration obtained after enzymatic hydrolysis was $36.54 \mathrm{~g} / \mathrm{dm}^{3}$ (Figure 1).

Comparable results were also obtained by Świątek and Lewandowska [18], who subjected rapeseed straw to hydrolysis. The efficiency of the saccharification process of the material in the native form was $16.0 \%$ of the theoretical efficiency from glucose. In their study, Perez et al. [19] focused on the optimization of wheat hydrolysis using heat treatment. The efficiency of biodegradation of this material prior to its pretreatment was $13.0 \%$ of the theoretical glucose value. Fu and Mazza [20] in a study of pretreatment of triticale straw subjected the material to enzymatic hydrolysis after its purification using different concentrations of 1-ethyl-3-methylimidazolium acetate. The hydrolysis 
efficiency was measured based on concentration of the obtained reducing sugars, depending on the amount of the ionic liquid used. The highest values $(81 \%)$ were observed for the sample, where the addition of ionic liquid in the solution was $50 \%$.

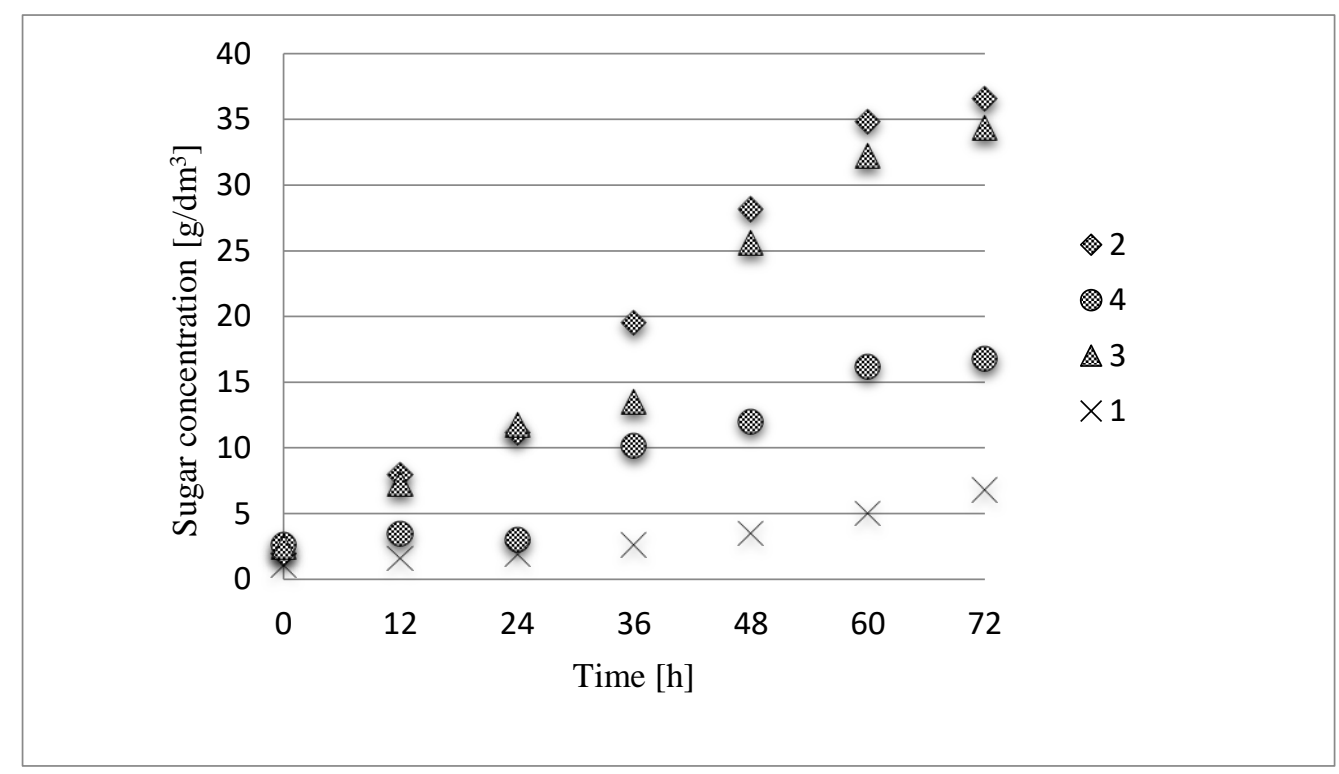

Figure 1. The concentration of sugars obtained after the enzymatic hydrolysis process of triticale straw: 1-control sample, without pretreatment; 2-after pretreatment with ionic liquid; 3-after chemical pretreatment (sulfate method); 4—after pretreatment using recycled ionic liquid.

In comparison, in the sample of straw not subjected to treatment to only $15.4 \%$ of the total amount of reducing sugars was obtained. The straw sample after pretreatment using $2 \%$ sulfuric acid (purification temperature: $160^{\circ} \mathrm{C}$, purification time: $20 \mathrm{~min}$ ) added to the aqueous solution of the material was also subjected to enzymatic hydrolysis. The yield of reducing sugars in the sample was $47 \%$. To obtain simple sugars for the production of bioethanol, Ang et al. [21] utilized rice husks. The highest concentration of reducing sugars- $42.1 \%$-was obtained in the sample with rice husks purified via the use of 1-ethyl-3-methylimidazolium acetate. 1-Ethyl-3-methylimidazolium acetate was also used for the pretreatment of barley straw by Sáez et al. [22]. These authors focused on the influence of time and temperature of pretreatment on the reducing sugar content measured after enzymatic hydrolysis. The highest glucose content was found in samples of barley straw pretreated with the ionic liquid at $110{ }^{\circ} \mathrm{C}$. The glucose in those samples was $400 \mathrm{mg} / 100 \mathrm{~g}$ of biomass after $30 \mathrm{~min}$ and $600 \mathrm{mg} / 100 \mathrm{~g}$ of biomass after $60 \mathrm{~min}$ of the pretreatment. Liu and Chen [4] conducted a study using (1-butyl-3-methylimidazolium chloride) ionic liquid where they subjected wheat straw to treatment. These authors found that the pretreatment with ionic liquid influences the depolymerization of cellulose, thus increasing its susceptibility to enzymatic hydrolysis. The efficiency of enzymatic hydrolysis was highest $(70.37 \%)$ in the wheat straw sample which was incubated with ionic liquid for $10 \mathrm{~min}$. Li et al. [23] attempted saccharification of wheat straw, which was previously treated using 1-ethyl-3-methylimidazolium phosphate and 1-ethyl-3-methylimidazolium acetate. The reducing sugar content measured after $12 \mathrm{~h}$ hydrolysis of wheat straw samples, previously purified using 1-ethyl-3-methylimidazolium phosphate was $4.8 \mathrm{mg} / \mathrm{cm}^{3}$, and in the sample of the material purified with 1-ethyl-3-methylimidazolium acetate the level of reducing sugars amounted to $3.2 \mathrm{mg} / \mathrm{cm}^{3}$. As a result of the conducted experiments, a minimum of two fold higher values for the triticale straw after $12 \mathrm{~h}$ enzymatic hydrolysis were obtained. The pretreatment of lignocellulose raw materials using ionic liquid is an innovative solution, thus far not used at an industrial scale. The study results confirm the favorable effect of this catalyst on the yield of reducing sugars in the hydrolysis process in comparison to samples without pretreatment. The use of this type of treatment at an industrial scale 
would only be possible if the efficiency of the method at least equaled the pretreatments. For these reasons an experiment which compared the yield of reducing sugars after enzymatic hydrolysis process of rye straw subjected to pretreatment with ionic liquid and using sulfate method (chemical pretreatment) was conducted. The content of reducing sugars measured after enzymatic hydrolysis in the sample of triticale straw purified using the sulfate method was $34.35 \mathrm{~g} / \mathrm{dm}^{3}$, and the sample of this material purified with ionic liquid contained $36.54 \mathrm{~g} / \mathrm{dm}^{3}$ reducing sugars. The mean values of the enzymatic hydrolysis products in these materials indicate that both methods of pretreatment have similar significance and both have a positive impact on the enhancement of the reducing sugar production process. However, pretreatment with ionic liquid is more favorable due to its lack of toxicity toward the environment. In the work of Chrzanowska et al. [24] the influence of imidazolium liquids on the efficiency of wastewater treatment and enzymatic activity of activated sludge microorganisms were examined. During the experiments it was observed that after a certain amount of time the activated sludge microorganisms adapted to the environment containing ionic liquid, and their composition did not differ significantly from the initial composition. Moreover, the rates of the nitrification processes and biochemical reactions were not reduced, which indicates the possibility of an efficient treatment of wastewater containing ionic liquids. The study published by Grabińska-Sota [25], also concerning the biodegradability of imidazolium ionic liquid confirm that the ionic liquid was subjected to quite considerable biological decomposition within the activated sludge, which most likely stemmed from the biodegradation of these compounds by microorganisms. The literature also contains studies where the lignocellulose material was subjected to pretreatment using sulfuric acid, sodium hydroxide or calcium hydroxide prior to enzymatic hydrolysis. Chen et al. [26] used $2 \% \mathrm{NaOH}$ for the pretreatment of corn straw, which was incubated in the solution for $1 \mathrm{~h}$ at $80^{\circ} \mathrm{C}$. The use of such pretreatment allowed them to increase the content of reducing sugars determined after enzymatic hydrolysis as compared to the native material. The sugar content was $89.5 \mathrm{~g} / \mathrm{dm}^{3}$, whereas the glucose content in the sample was $56.7 \mathrm{~g} / \mathrm{dm}^{3}$, and the efficiency of hydrolysis was $83.3 \%$. Sun and Cheng [27] performed enzymatic hydrolysis of rye straw and increased its susceptibility to saccharification via purification in a solution of $\mathrm{H}_{2} \mathrm{SO}_{4}$. The content of reducing sugars depended on the concentration of $\mathrm{H}_{2} \mathrm{SO}_{4}$ used to purify the rye straw. In the sample of rye straw purified with $1.5 \% \mathrm{H}_{2} \mathrm{SO}_{4}$, the content of reducing sugars was $159.7 \mathrm{mg} / \mathrm{g}$ after $30 \mathrm{~min}$ and $197 \mathrm{mg} / \mathrm{g}$ after $90 \mathrm{~min}$ of pretreatment. In the sample of the material pretreated with $0.6 \% \mathrm{H}_{2} \mathrm{SO}_{4}$, the content of reducing sugars was $125 \mathrm{mg} / \mathrm{g}$ after $30 \mathrm{~min}$ and $136 \mathrm{mg} / \mathrm{g}$ after $90 \mathrm{~min}$ of pretreatment.

The main limitation of the use of ionic liquid at an industrial scale is its high price. The increasing interest of the industry in these solvents, their wide and easy use and lack of toxicity for the environment constitutes the basis for the statement that the price of ionic liquid may be reduced in the future [28]. Another method for the reduction of the cost of industrial use of ionic liquids is the development of an efficient method for their recycling and reuse in another process. Based on the above statements, a study was implemented concerning purification of the ionic liquid-1-ethyl-3-methylimidazolium acetate after the purification process of rye straw and its reuse for the pretreatment of a new portion of the lignocellulose material. The efficiency of rye straw pretreatment using recycled ionic liquid was evaluated comparing the yield of reducing sugars after enzymatic hydrolysis of the material. The majority of the cellulose fraction of the biomass is retrieved from the ionic liquid via addition of a so called non-solvent. Water can be such a non-solvent for imidazolium ionic liquids, which, by precipitating cellulose from the solution, creates one phase with the ionic liquid. The cellulose from such a mixture was removed by filtration or centrifugationn. The water remaining in the solution was removed via lyophilization. As a result of lyophilization, a yellow-brown ionic liquid was obtained, with a color similar to that of a pure ionic liquid. The mean content of reducing sugars obtained after enzymatic hydrolysis of rye straw purified with recycled ionic liquid was $16.77 \mathrm{~g} / \mathrm{dm}^{3}$, that is approx. $52 \%$ lower than the mean content of reducing sugars obtained through hydrolysis of rye straw purified with the pure ionic liquid. Xu et al. [29] subjected eucalyptus samples to purification and enzymatic hydrolysis. The purification was conducted using 
pure and recycled ionic liquids (AMIMOAc and EMIMOAc). The ionic liquid recycling was conducted by vacuum drying. These authors demonstrated that both pretreatment with pure ionic liquid and recycled ionic liquid influences the change of the structure of cellulose in eucalyptus and improves the yield of reducing sugars after enzymatic hydrolysis. In order to attempt a classification of the types of treatments of lignocellulose materials in terms of obtaining the highest concentration of reducing sugars after enzymatic hydrolysis process, the obtained results were analyzed using the Principal Components Analysis (PCA) method. The active variables consisted in the reducing sugars concentration values determined at specific time intervals. The grouping variables were three types of pretreatment used prior to the hydrolysis process: treatment using ionic liquid, using recycled ionic liquid, sulfate method treatment and sample with the native material, i.e., not subjected to any pretreatment. Results of reducing sugars determined in three repetitions, for each time interval, were used for the PCA analysis conducted in the present study. The PCA analysis was conducted based on a correlation matrix. From the set of the analyzed data four factors were obtained with values $>1$, which characterized samples after pretreatment in the sense of their similarities and differences. They explained a total of $97.43 \%$ of the total variability, and $90.37 \%$ of the variability could be explained by the single main component $Z 1$. The second distinguished component $Z 2$ explained $7.06 \%$, and the Z3 component slightly over $1 \%$. Data dimension reduction was conducted based on a screening plot (Figure 2). The moment of graph flattening is visible after the second component, thus the subsequent analyses were conducted on this basis, referring solely to the influence of components Z1 and Z2.

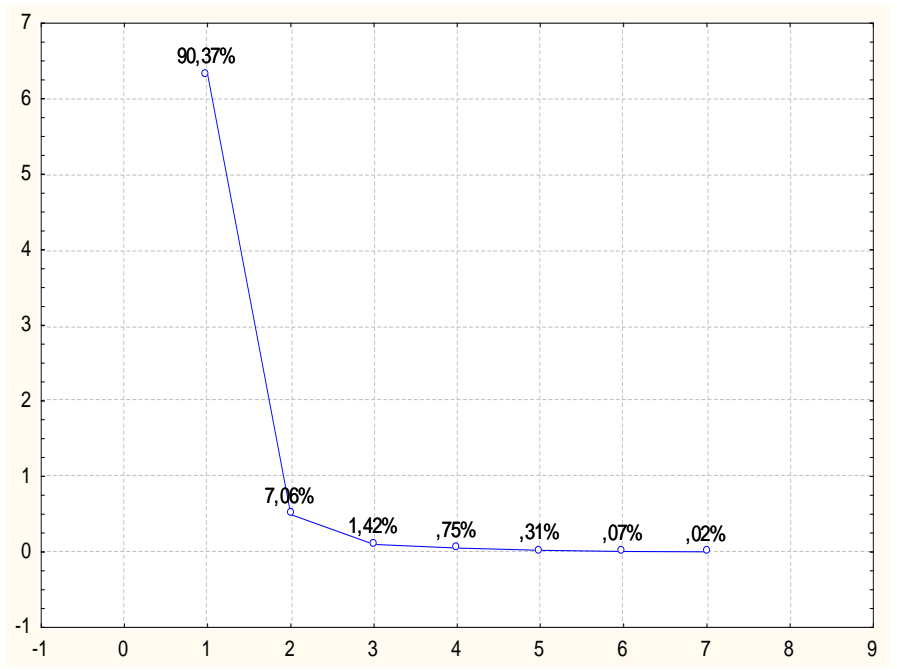

Figure 2. Screen for variables describing enzymatic hydrolysis process.

In order to investigate the influence of pretreatment of lignocellulose materials subjected to enzymatic hydrolysis for the content of reducing sugars, an observation chart (Figure 3) was drawn up, which presents the location of the grouped variables in the new dimensional space defined by the components $\mathrm{Z} 1$ and $\mathrm{Z} 2$ determined during the analysis. The resemblance measure during the analysis was the Euclidean distance. An analysis of the chart indicated the existence of three groups. First group was characterized by the triticale straw samples subjected to pretreatment using ionic liquid (CJ1-3) and samples of the same material treated with sulfate method (SO41-3). The second group consisted of triticale straw samples purified using recycled ionic liquid (CR1-3). Third group contains triticale straw samples subjected to enzymatic hydrolysis without pretreatment. Enzymatic hydrolysis of samples from the first group had the best efficiency due to the better availability of cellulose for the enzymes. Thus, the Euclidean distance of these samples from the $\mathrm{O}$ sample is highest (Figure 3).

The use of pretreatment with ionic liquid or sulfate method has a similar effect on the concentration of reducing sugars obtained after enzymatic hydrolysis. The Z1 component allows one to distinguish the type of pretreatment used and indicates the increase of reducing sugars in the given time intervals 
of enzymatic hydrolysis. On the other hand, the Z2 component informs on the level of cellulose decomposition to simple sugars.

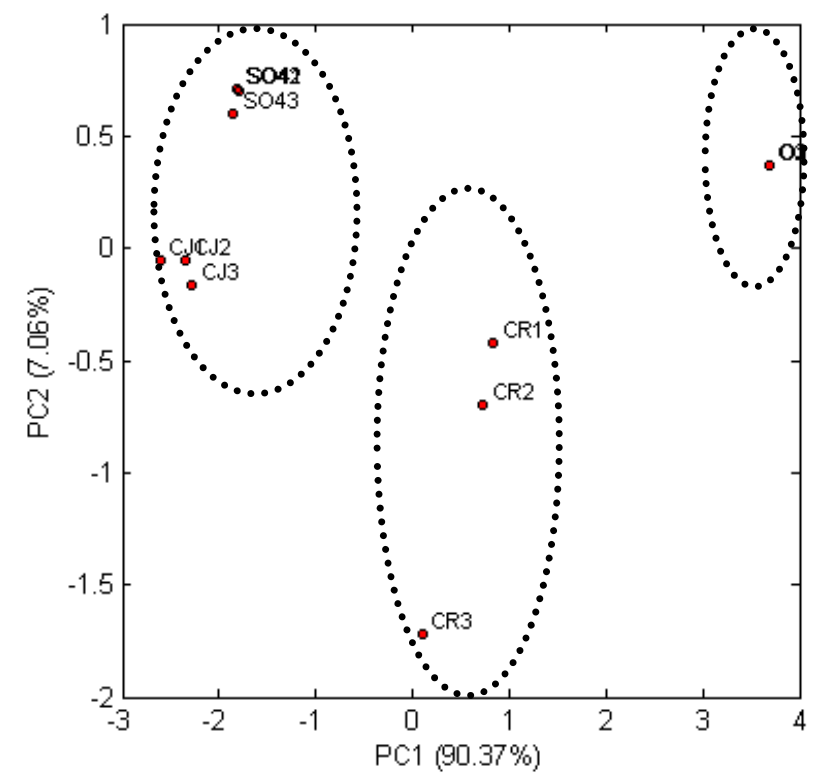

Figure 3. PCA scores plot of triticale straw pretreated with ionic liquid, recycled ionic liquid, sulfate method, untreated (control).

The results of the statistical tests corroborate the validity of using triticale straw pretreatment with ionic liquid and classify the type of used treatments and their influence on the formation reducing sugars in the process of enzymatic hydrolysis. Triticale straw pretreatment with ionic liquid has a significant impact on the reducing sugar content, and its increase is comparable to the increase of reducing sugars in the triticale straw sample purified using the sulfate method. In summary, triticale straw pretreatment has a significant impact on formation of reducing sugars by enzymatic hydrolysis. Weaker results are obtained in samples purified with ionic liquid after its dehydration.

\subsection{Alcoholic Fermentation}

Samples of triticale straw purified with ionic liquid and using the sulfate method and recycled ionic liquid were subjected to alcoholic fermentation. For comparison, a sample of triticale straw not subjected to pretreatment was also fermented (control sample).

The highest concentration of ethyl alcohol $\left(10.64 \mathrm{~g} / \mathrm{dm}^{3}\right)$ was demonstrated in the sample of triticale straw purified with ionic liquid (Figure 4). For comparison, the content of ethyl alcohol in the control sample was $1.60 \mathrm{~g} / \mathrm{dm}^{3}$. These differences result from the fact, that the hydrolysate of triticale straw purified with ionic liquid was characterized by a higher concentration of reducing sugars, as well as lower lignin content, which blocks the functioning of yeasts in mash.

The hydrolysate of triticale straw purified using the sulfate method, after fermentation was characterized by an ethanol content of $5.46 \mathrm{~g} / \mathrm{dm}^{3}$. Similar results were obtained for triticale straw samples subjected to pretreatment with recycled ionic liquid. The concentration of ethanol in this sample was $5.39 \mathrm{~g} / \mathrm{dm}^{3}$. The vitality of yeasts in both samples was lower than in the remaining hydrolysates ( $60 \%$ for sulfate method purified straw and $65 \%$ for recycled ionic liquid purified straw) (Table 1). 


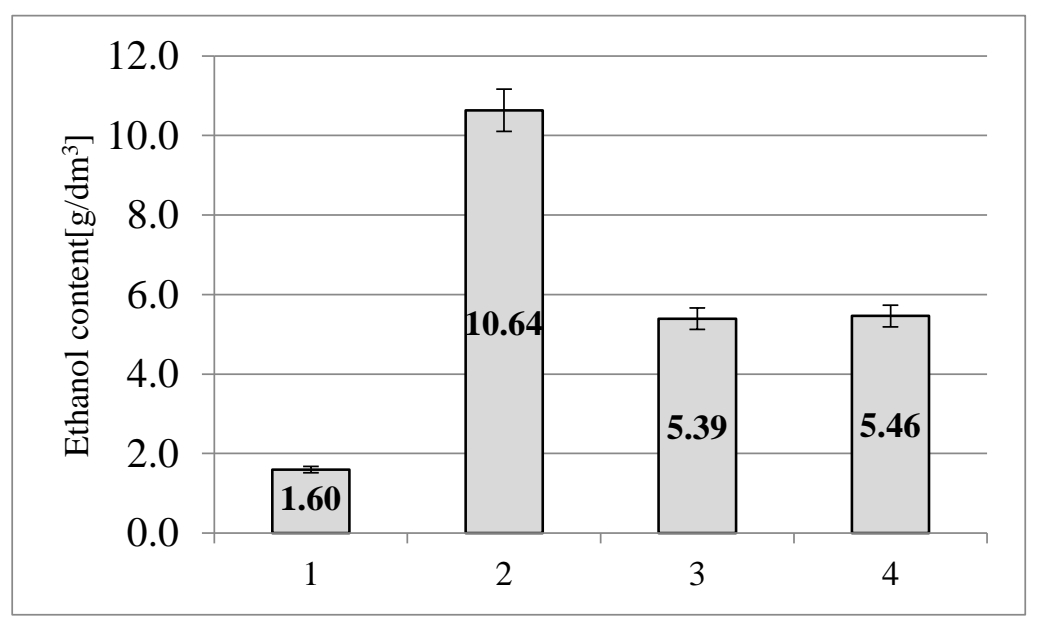

Figure 4. Concentration of ethyl alcohol after $96 \mathrm{~h}$ of alcoholic fermentation of triticale straw: 1-control sample; 2-pretreated with ionic liquid; 3 - pretreated with white bleach (sulfate method); 4 -pretreated with recycled ionic liquid.

Table 1. Count and vitality of Saccharomyces cerevisiae Ethanol Red yeast cells in the tested mashes.

\begin{tabular}{ccc}
\hline Fermented medium & Count [cfu/mL & Vitality [\%] \\
\hline Triticale straw-control sample & $4.8 \times 10^{5}$ & $40 \pm 1.5$ \\
Triticale straw-ionic liquid treatment & $1.2 \times 10^{8}$ & $96 \pm 0.5$ \\
Triticale straw-sulfate method treatment & $7.2 \times 10^{5}$ & $60 \pm 0.7$ \\
Triticale straw-recycled ionic liquid treatment & $7.8 \times 10^{5}$ & $65 \pm 1.2$ \\
\hline
\end{tabular}

Analysis of the count and vitality of yeasts performing the fermentation process allows us to conclude that the release of inhibitors in the sulfate method had a negative influence on the growth and vitality of the microorganisms engaged in the fermentation process. Similar conclusions were drawn by Szymanowska et al. [30], who to produce bioethanol used potato pulp hydrolyzed using sulfuric acid and enzymes. The acidic hydrolysate contained $22 \mathrm{~g} / \mathrm{dm}^{3}$ reducing sugars, from which only $6 \mathrm{~g} / \mathrm{dm}^{3}$ ethanol was obtained as a result of fermentation. Furthermore, the authors determined that the cost of obtaining hydrolysates using amylases, cellulases and pectinases is not comparable to the efficiency of the process. The concentration of ethanol after fermentation of enzymatic hydrolysates was not higher than $2.5 \%$, which, including the process costs such as separation and concentration of the final product becomes unprofitable. Perhaps the use of membrane distillation will contribute to reduction of the process costs in the future [30]. The literature contains an increasing number of solutions aiming at purification of the substrate prior to fermentation process. The most commonly described methods include detoxification via using bases, reducing agents and polymers. Worth mentioning is the fact that screening of microorganisms immune to environmental stresses, selection of the culture method, microbial treatment, evolutionary engineering and genetic engineering are also among methods, which aim at increase of the efficiency of the use of lignocellulose [31]. For comparison Saha et al. [32] fermented wheat straw using Saccharomyces cerevisiae yeast in two systems: SHF-separate hydrolysis and fermentation process SSF-simultaneous hydrolysis and fermentation process. The wheat straw was previously purified with sulfuric acid and enzymatically hydrolyzed to obtain reducing sugars. In addition, the authors subjected to fermentation a sample of wheat straw which apart from acid was also purified with lime. As a result of the conducted study it was determined that the ethanol content did not depend on the system of fermentation and only on the method of material purification. In the simultaneous hydrolysis and fermentation of the samples, which were subjected to pretreatment using sulfuric acid and enzymes, the ethanol content was $13 \mathrm{~g} / \mathrm{dm}^{3}$ and in the variant with additional lime purification $17 \mathrm{~g} / \mathrm{dm}^{3}$ ethanol was obtained. 
The influence of pretreatment of lignocellulose material on the efficiency of alcoholic fermentation was also tested by Eisenhuber et al. [33], who conducted their study on an industrial scale. They obtained ethanol from different types of straw (wheat, rye and corn). Prior to fermentation, they used pretreatment with high temperature $\left(160-200^{\circ} \mathrm{C}\right)$ for 10 and $20 \mathrm{~min}$. Alcoholic fermentation was conducted using Saccharomyces cerevisiae at $30^{\circ} \mathrm{C}$ for $168 \mathrm{~h}$. In the sample of rye straw subjected to pretreatment in temperature $200{ }^{\circ} \mathrm{C}$ for $10 \mathrm{~min} 108 \mathrm{~kg}$ of ethanol was obtained, and the efficiency of fermentation amounted to $44 \%$ of theoretical value. For rye straw pretreated at $200{ }^{\circ} \mathrm{C}$ for a longer period (20 $\mathrm{min}$ ) the content of ethanol was $169 \mathrm{~kg}$, and the efficiency of fermentation was at $70 \%$ of the theoretical value level. Kádár et al. [34] conducted simultaneous hydrolysis and fermentation of cellulose industrial waste (corrugated cardboard, cellulose sludge formed during paper production) originating from the Hungarian company Dunapack (Ujazd, Poland) and SOLKA FLOC 200 cellulose powder (International Fiber Corporation, New York, North Tonawanda, USA). In the samples fermented by S. cerevisiae, the ethanol content was $14.2 \mathrm{~g} / \mathrm{dm}^{3}$ for corrugated cardboard, $9.0 \mathrm{~g} / \mathrm{dm}^{3}$ for cellulose sludge and $16.6 \mathrm{~g} / \mathrm{dm}^{3}$ for SOLKA FLOC 200cellulose powder. In the present study, the ethanol content differed considerably. For these reasons, an attempt was made to demonstrate the relationship between ethanol concentration and the hydrolysate type subjected to alcoholic fermentation, for which the PCA method was used. The active variables consisted of the concentration of ethyl alcohol obtained after fermentation and the grouping variable was type of pretreatment of triticale straw, which influenced not only the reducing sugars concentration after enzymatic hydrolysis, but also the content of ethanol after fermentation. In this case, the PCA analysis was also conducted based on a correlation matrix. From the analyzed data two first coefficients with values of above $>1$ were generated, characterizing hydrolysate samples in terms of similarities and differences. In this case the main component Z1 explained as much as $96.95 \%$ of the total variability (Figure 5).

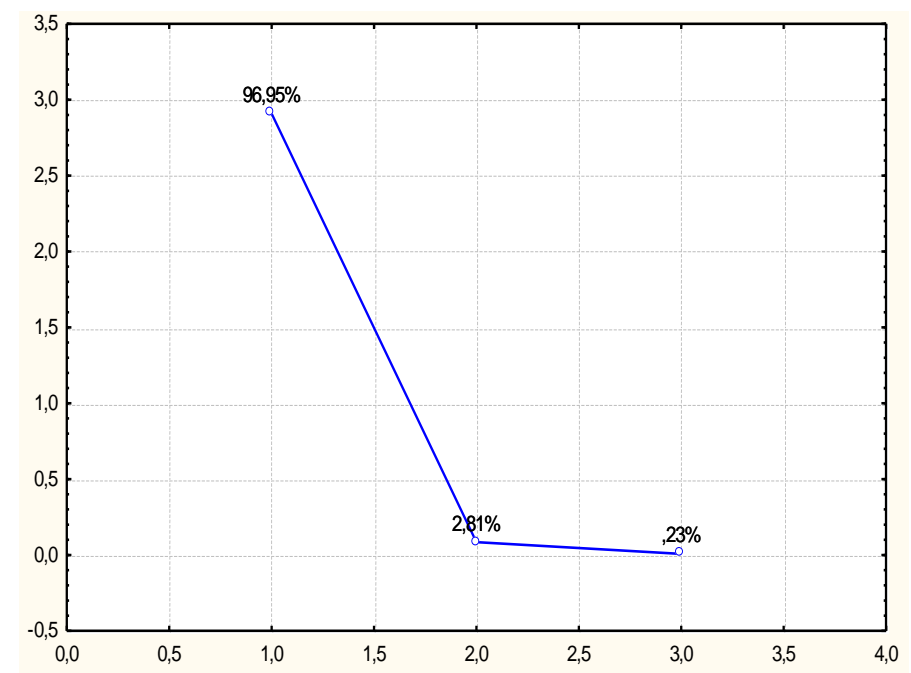

Figure 5. Screen for variables describing the changes in the concentration of ethyl alcohol after fermentation.

Figure 6 presents the influence of the used pretreatment of triticale straw on the ethanol concentration after fermentation. The location of grouping variables is presented in a new coordinate system, defined by the $\mathrm{Z} 1$ and $\mathrm{Z} 2$ components. The measure of resemblance in this statistical method is the Euclidean distance. The coefficient loads for the $\mathrm{Z} 1$ component indicated its relationship with the ethanol concentration values in the tested hydrolysates. Classification using the PCA method allowed re-establishing three groups of samples subjected to fermentation. The first group consisted of control samples of triticale straw not subjected to pretreatment, which gave the lowest ethanol concentration. The second group consisted of triticale straw samples purified with recycled ionic liquid (CR) and 
samples of triticale straw purified using the sulfate method $\left(\mathrm{SO}_{4}\right)$. The third group- triticale straw samples purified with ionic liquid (C)—were the samples with the highest ethanol content.

The most extreme location on the observation chart is taken by the samples marked as ' 0 ' and ' $\mathrm{CJ}$ '. This indicates the greatest differences between ethanol concentrations in these samples, which is linked to the use of pretreatment with ionic liquid. The highest increase of ethanol was observed for triticale straw subjected to ionic liquid treatment, the Euclidean distances of the remaining samples in relation to the control sample of triticale straw (0) are similar.

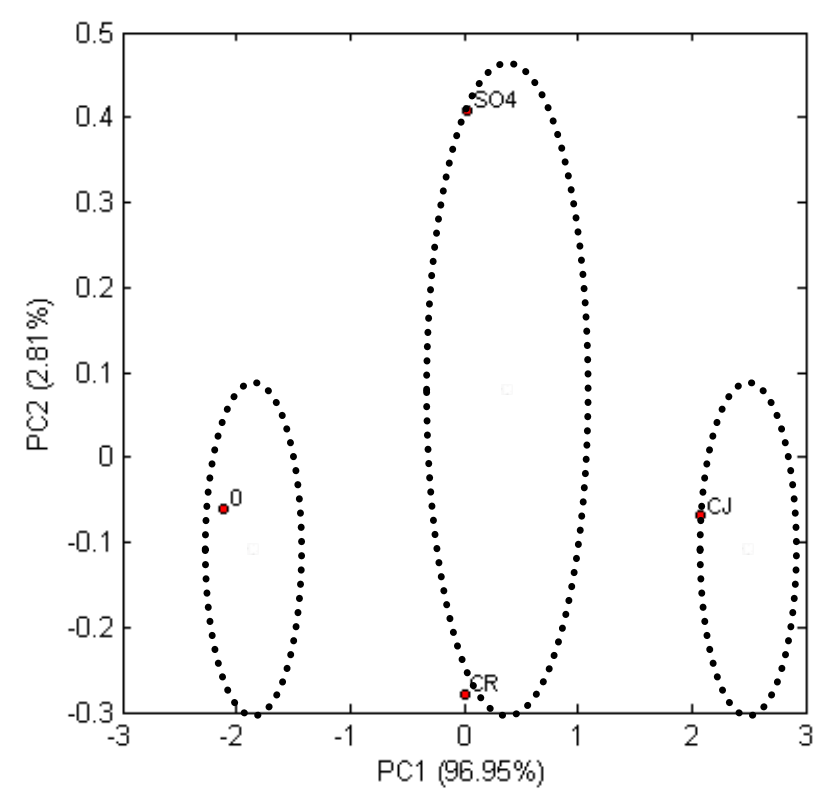

Figure 6. PCA scores plot of triticale straw pretreatment by ionic liquid, recycled ionic liquid or sulfate method, untreated (control).

Thus, the ethanol concentration in these samples has a similar level and it is strictly related to the content of reducing sugars in the mashes prior alcoholic fermentation. The PCA analysis results demonstrated that the content of reducing sugars in the samples of triticale straw is influenced by the use of ionic liquid for the pretreatment of these materials. The results of ethanol concentration in mashes are also highest for the samples purified with pure ionic liquid than in the samples, where white bleach is used for the treatment (sulfate method).

\section{Conclusions}

The highest concentration of reducing sugars was obtained through enzymatic hydrolysis of triticale straw purified with ionic liquid. The efficiency of enzymatic hydrolysis of triticale straw after pretreatment with ionic liquid and sulfate method was similar. Ionic liquid recycling after pretreatment of rye straw using lyophilization allowed to reuse this solvent to purify rye straw, yet the efficiency of this method remained at a low level. The concentrations of ethanol in mashes were higher in the samples of triticale straw purified with ionic liquid, in comparison to the samples of these materials pretreated using the sulfate method or recycled ionic liquid. The use of ionic liquid-1-ethyl-3-methylimidazolium acetate enhanced the yield of ethanol from triticale straw from $1.60 \mathrm{~g} / \mathrm{dm}^{3}$ after processing without pre-treatment to $10.64 \mathrm{~g} / \mathrm{dm}^{3}$ after pre-treatment.

Author Contributions: Conceptualization, Methodology, Results and formal analysis and Writing-Original Draft Preparation M.S.-K., D.S.-P., J.C.-P., B.W., J.K.-C., M.W., J.W.; Results analysis, software and plotting figures of the obtained analytical and numerical B.W., M.S.-K.; Writing Review and Editing J.C.-P., D.S.-P.; All authors read and approved the final manuscript.

Funding: This research was funded by National Science Center grant number DEC- 2017/01/X/NZ9/00357. 
Conflicts of Interest: The authors declare no conflict of interest.

\section{References}

1. Jönsson, L.J.; Martín, C. Pretreatment of lignocellulose: Formation of inhibitory by-products and strategies for minimizing their effects. Bioresour. Technol. 2016, 199, 103-112. [CrossRef]

2. Naik, S.N.; Goud, V.V.; Rout, P.K.; Dalai, A.K. Production of first and second generation biofuels: A comprehensive review. Renew. Sustain. Energy. Rev. 2010, 14, 578-597. [CrossRef]

3. Chandel, A.K.; Kapoor, R.K.; Singh, A.; Kuhad, R.C. Detoxification of sugarcane bagasse hydrolysate improves ethanol production by Candida shehatae NCIM 3501. Bioresour. Technol. 2007, 98, 1947-1950. [CrossRef]

4. Liu, L.; Chen, H. Enzymatic hydrolysis of cellulose materials treated with ionic liquid [BMIM] Cl. Chin. Sci. Bull. 2006, 51, 2432-2436. [CrossRef]

5. Berlin, A.; Balakshin, M.; Gilkes, N.; Kadla, J.; Maximenko, V.; Kubo, S.; Saddler, J. Inhibition of cellulase, xylanase and $\beta$-glucosidase activities by softwood lignin preparations. J. Biotechnol. 2006, 125, $198-209$. [CrossRef] [PubMed]

6. Mosier, N.; Wyman, C.; Dale, B.; Elander, R.; Lee, Y.Y.; Holtzapple, M.; Ladisch, M. Features of promising technologies for pretreatment of lignocellulosic biomass. Bioresour. Technol. 2005, 96, 673-686. [CrossRef] [PubMed]

7. Plechkova, N.V.; Seddon, K.R. Applications of ionic liquids in the chemical industry. Chem. Soc. Rev. 2008, 37, 123-150. [CrossRef] [PubMed]

8. Pinkert, A.; Marsh, K.N.; Pang, S.; Staiger, M.P. Ionic liquids and their interaction with cellulose. Chem. Rev. 2009, 109, 6712-6728. [CrossRef]

9. Zhu, S.; Wu, Y.; Chen, Q.; Yu, Z.; Wang, C.; Jin, S.; Ding, Y.; Wu, G. Dissolution of cellulose with ionic liquids and its application: A mini-review. Green Chem. 2006, 8, 325-327. [CrossRef]

10. Endres, F.; El Abedin, S.Z. Air and water stable ionic liquids in physical chemistry. Phys. Chem. Chem. Phys. 2006, 8, 2101-2116. [CrossRef]

11. Huddleston, J.G.; Visser, A.E.; Reichert, W.M.; Willauer, H.D.; Broker, G.A.; Rogers, R.D. Characterization and comparison of hydrophilic and hydrophobic room temperature ionic liquids incorporating the imidazolium cation. Green Chem. 2001, 3, 156-164. [CrossRef]

12. Mäki-Arvela, P.; Anugwom, I.; Virtanen, P.; Sjöholm, R.; Mikkola, J.P. Dissolution of lignocellulosic materials and its constituents using ionic liquids-A review. Ind. Crops. Prod. 2010, 32, 175-201. [CrossRef]

13. Kolodziej, B.M.M. The Renewable Energy Sources. Agricultural Energy Resources; Universal Agricultural and Forest Publishing: Poznan, Poland, 2012.

14. Sims, R.E.H.; Mabee, W.; Saddler, J.N.; Taylor, M. An overview of second generation biofuel technologies. Bioresour. Technol. 2010, 101, 1570-1580. [CrossRef]

15. Hendriks, A.T.W.M.; Zeeman, G. Pretreatments to enhance the digestibility of lignocellulosic biomass. Bioresour. Technol. 2009, 100, 10-18. [CrossRef]

16. Zhang, Y.H.P. Reviving the carbohydrate economy via multi-product lignocellulose biorefineries. J. Ind. Microbiol. Biotechnol. 2008, 35, 367-375. [CrossRef]

17. Ghose, T.K. Measurement of cellulase activities. Pure Appl. Chem. 1987, 59, 257-268. [CrossRef]

18. Świątek, M.; Lewandowska, M.B.W. The importance of selecting the method of pre-treatment of lignocellulosic substrates, taking into account the efficiency of bioethanol production. Adv. Agri. Sci. 2011, 63, 109-119.

19. Pérez, J.A.; Ballesteros, I.; Ballesteros, M.; Sáez, F.; Negro, M.J.; Manzanares, P. Optimizing Liquid Hot Water pretreatment conditions to enhance sugar recovery from wheat straw for fuel ethanol production. Fuel 2008, 87, 3640-3647. [CrossRef]

20. Fu, D.; Mazza, G. Aqueous ionic liquid pretreatment of straw. Bioresour. Technol. 2011, 102, $7008-7011$. [CrossRef]

21. Ang, T.; Ngoh, G.; Chua, A.S.; Lee, M. Elucidation of the effect of ionic liquid pretreatment on rice husk via structural analyses. Biotechnol. Biofuels 2012, 5, 67. [CrossRef]

22. Sáez, F.; Ballesteros, M.; Ballesteros, I.; Manzanares, P.; Oliva, J.M.; Negro, M.J. Enzymatic hydrolysis from carbohydrates of barley straw pretreated by ionic liquids. J. Chem. Technol. Biotechnol. 2013, 88, 937-941. [CrossRef] 
23. Li, Q.; He, Y.C.; Xian, M.; Jun, G.; Xu, X.; Yang, J.M.; Li, L.Z. Improving enzymatic hydrolysis of wheat straw using ionic liquid 1-ethyl-3-methyl imidazolium diethyl phosphate pretreatment. Bioresour. Technol. 2009, 100, 3570-3575. [CrossRef]

24. Chrzanowska, M.; Łuczak, J.H.J. Purification of wastewater containing ionic liquid with activated sludge. Ecol. Eng. 2006, 14, 70-75.

25. Grabińska-Sota, E. The influence of quaternary ammonium salts on the operation of wastewater treatment plants. Chem. Ind. 2010, 89, 1437-1439.

26. Chen, M.; Zhao, J.; Xia, L. Comparison of four different chemical pretreatments of corn stover for enhancing enzymatic digestibility. Biomass Bioenergy 2009, 33, 1381-1385. [CrossRef]

27. Sun, Y.; Cheng, J.J. Dilute acid pretreatment of rye straw and bermudagrass for ethanol production. Bioresour. Technol. 2005, 96, 1599-1606. [CrossRef] [PubMed]

28. Khodadoust, A.P.; Yachandrasekaran, S.; Dionysiou, D.D. Preliminary assessment of imidazolium-based room-temperature ionic liquids for extraction of organic contaminants from soils. Environ. Sci. Technol. 2006, 40, 2339-2345. [CrossRef]

29. Xu, J.; Bingchuan, L.; Hou, H.; Hu, J. Pretreatment of eucalyptus with recycled ionic liquids for low-cost biorefinery. Bioresour. Technol. 2017, 234, 406-414. [CrossRef]

30. Szymanowska, D.; Dróżdżyńska, A.; Lewandowicz, G. The potato pulp as a raw material for bioethanol production. Lett. Sci. Univ. Econ. Poz. 2011, 206, 234-242.

31. Lewandowicz, G.; Białas, W.; Marczewski, B.; Szymanowska, D. Application of membrane distillation for ethanol recovery during fuel ethanol production. J. Memb. Sci. 2011, 375, 212-219. [CrossRef]

32. Saha, B.C.; Iten, L.B.; Cotta, M.A.; Wu, Y.V. Dilute acid pretreatment, enzymatic saccharification and fermentation of wheat straw to ethanol. Process Biochem. 2005, 40, 3693-3700. [CrossRef]

33. Eisenhuber, K.; Jäger, A.; Wimberger, J.; Kahr, H. Comparison of different pretreatment methods for straw for lignocellulosic bioethanol production. Agron. Res. 2013, 11, 173-182.

34. Kádár, Z.; Szengyel, Z.; Réczey, K. Simultaneous saccharification and fermentation (SSF) of industrial wastes for the production of ethanol. Ind. Crops. Prod. 2004, 20, 103-110. [CrossRef]

(C) 2019 by the authors. Licensee MDPI, Basel, Switzerland. This article is an open access article distributed under the terms and conditions of the Creative Commons Attribution (CC BY) license (http:/ / creativecommons.org/licenses/by/4.0/). 